\title{
Single Incision Gasless Laparoscopic Myomectomy
}

\author{
Gnanaraj Jesudian
}

\begin{abstract}
Uterine fibroids are a common finding in women presenting for evaluation of infertility. Laparoscopic myomectomy has now become an accepted procedure in urban areas as many of the women prefer minimally invasive procedures. We describe the method of doing single incision laparoscopic myomectomy that offers all the advantages at a fraction of the cost of laparoscopic surgery in urban areas.
\end{abstract}

Keywords: Gasless laparoscopic surgeries, Low cost, Single incision laparoscopic surgery (SILS).

How to cite this article: Jesudian G. Single Incision Gasless Laparoscopic Myomectomy. Int J Infertil Fetal Med 2015;6(2): 84-87.

Source of support: Nil

Conflict of interest: None

Date of received: $29-05-15$

Date of acceptance: 18-07-15

Date of publication: August 2015

\section{INTRODUCTION}

Uterine fibroids are the most common benign tumors occurring in women in the reproductive age group. The prevalence rates quoted in literature range from 20 to $50 \%$, based on postmortem studies. ${ }^{1}$ The prevalence varies with age, with an increase in the late reproductive period. Uterine fibroids are detected in a significant number of infertile women. ${ }^{2}$ The impact of fibroids on infertility is still controversial. ${ }^{2}$ Laparoscopic myomectomy was described for the first time in $1979 .{ }^{3}$ At present, laparoscopic myomectomy, in infertile patients, is one of the common surgical procedures. ${ }^{2}$ We describe our experience with gasless or lift laparoscopic myomectomies.

\section{METHODS}

After regional anesthesia the patient is placed in lithotomy position. The abdomen and perineum is cleaned

\section{Director and Adjunct Professor}

Department of Medical Services, Samiti for Education Environment Social and Health Action, Karunya University, Coimbatore Tamil Nadu, India

Corresponding Author: Gnanaraj Jesudian, Director andAdjunct Professor, Department of Medical Services, Samiti for Education Environment Social and Health Action, Karunya University, Coimbatore, Tamil Nadu, India, Phone: 9442543377 e-mail: jgnanaraj@gmail.com and draped. Hegar's uterine dilator is used to dilate the cervix and pass a uterine manipulator. Two towel clips are used to hold the lower half of the umbilicus, and an incision is made through the lower half. It is widened to pass a finger comfortably, and using this as the guide, the lift apparatus is placed, and the anterior abdominal wall is lifted under vision (Fig. 1).

The equipment used was originally designed by Dr Daniel Kruschinski and offered the best exposure among the various types of equipment available for gasless laparoscopic surgeries. ${ }^{4}$ This was modified by to make it user friendly and has the following components: ${ }^{5}$

- Attachment that fits to any type of operating table.

- An intra-abdominal portion to lift the anterior abdominal wall through the opening in the umbilicus.

- A connecting mechanism with a gear to lift the wall that locks in place with two click mechanisms.

- The hand instruments were designed similar to open surgical instruments but with a special curve and longer to make it user friendly for single incision surgeries.

The patient is placed in head down position to have the intestines move away from the field of vision. An atraumatic forceps could be used for this. The uterine manipulator is used to hold the uterus in a most convenient way to remove the myoma. A monopolar hook is used to make an incision over the uterus to reach the fibroid. Combination of blunt and sharp dissection is used for removing the fibroid (Figs 2 and 3). Sutures are placed to close the incision in the uterus using the regular long needle holder and number 1 Vicryl suture (Figs $4 \mathrm{~A}$ and B).

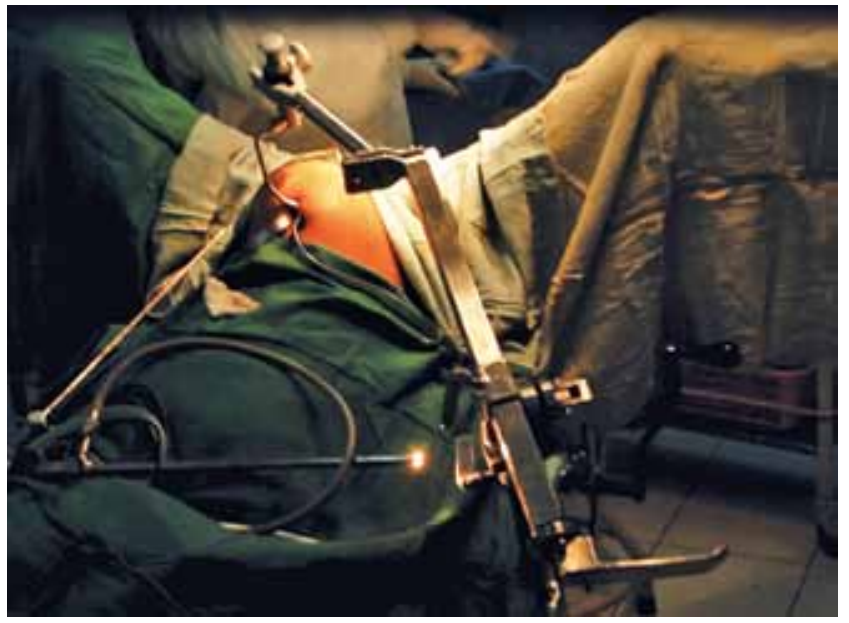

Fig. 1: Patient position 
The regular open needle holder is handled with the right hand while the left hand handles the uterine manipulator during suturing (Figs 5 and 6). Extracorporeal knotting is using along with pusher to tie the knots (Fig. 7). Sometimes an extra $5 \mathrm{~mm}$ port is used to facilitate suturing.

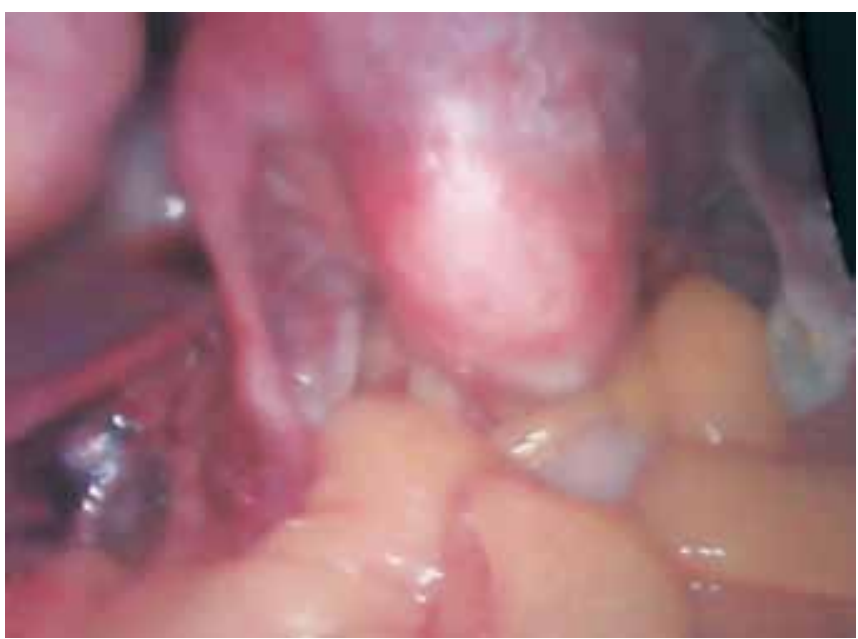

Fig. 2: Posterior fibroid

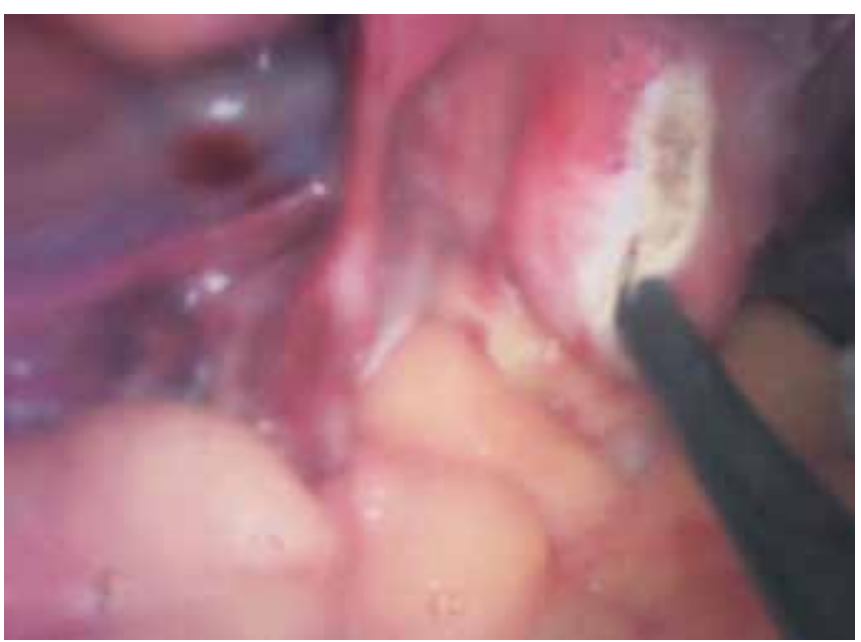

Fig. 3: Use of hook to dissect around the fibroid

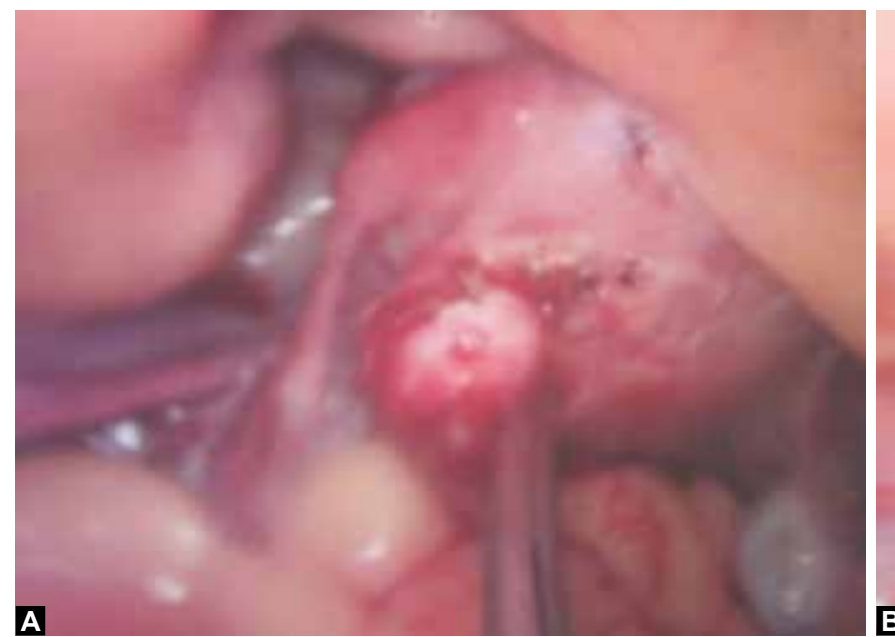

Figs 4A and B: (A) Removal the fibroid and (B) after removal of the fibroid

\section{RESULTS} them also had increased bleeding. 95 minutes.

\section{DISCUSSION} for knot tying.

Since May 2013, fifteen myomectomies were carried out by the Samiti for Education Environment Social and Health Action (SEESHA) team. The size of the myomas varied from $3 \mathrm{~cm}$ diameter to $12 \mathrm{~cm}$ in diameter and most of them were on the anterior surface or fundus of the uterus. Three of them were on the posterior surface. All the women had presented for infertility and ten of

All the surgeries were started with spinal anesthesia and one of them had general anesthesia as spinal anesthesia was not sufficient. None of them needed blood transfusion. The duration of surgery from skin to skin varied from 40 to 210 minutes and average duration was

Fibroids are present in approximately 5 to $10 \%$ of patients presenting with infertility, however they are the only factor in only about a fourth of them. ${ }^{6}$ Approximately $50 \%$ of the women with infertility and myomas become pregnant after myomectomy. As epidemiological studies have not been able to provide unflinching evidence of the impact of fibroids on fertility, a large number of studies have been based on pregnancy rates after myomectomy.

Donnez and Jadoul performed a literature review on both prospective and retrospective studies published between 1988 and 2001. The pregnancy rate in patients undergoing hysteroscopic and laparoscopic/abdominal myomectomy was 45 and $49 \%$, respectively. ${ }^{7}$

Single incision laparoscopic myomectomy is a recently described procedure. ${ }^{8,9}$ The team found suturing difficult and hence used barbed suture that eliminated the need

Gasless laparoscopic surgeries have several advantages over regular laparoscopic surgeries. For instance,

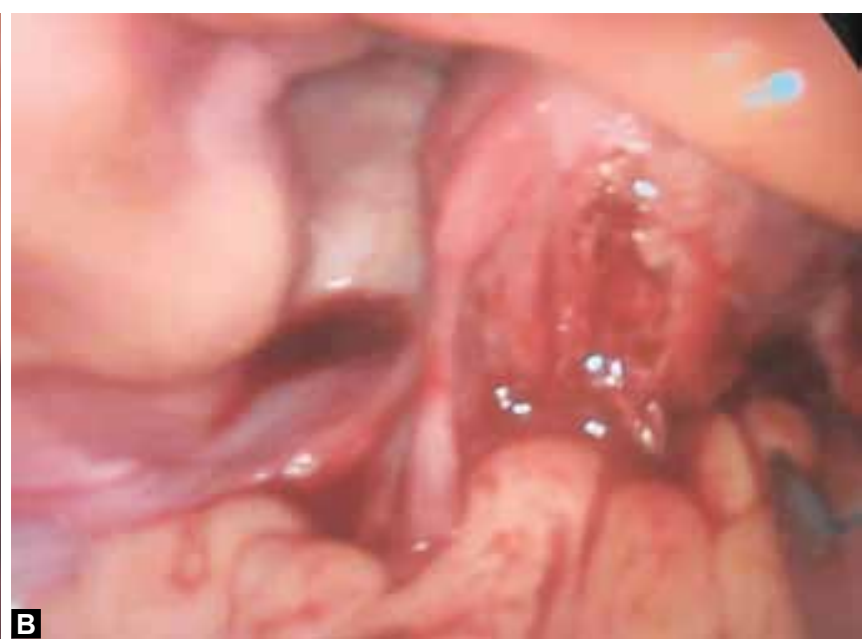

$2015 ; 6(2): 84-87$ 


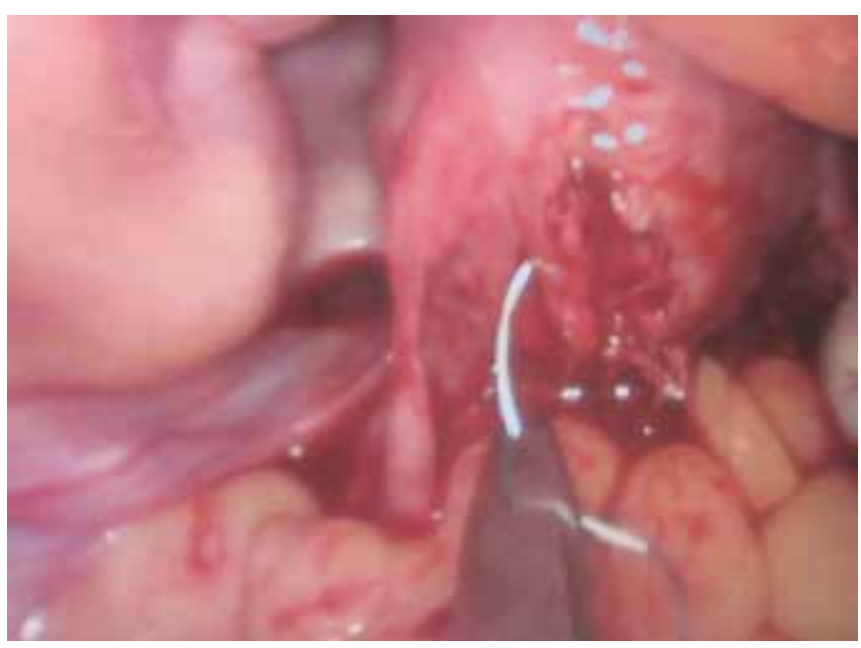

Fig. 5A: Suturing with laparoscopic needle holder

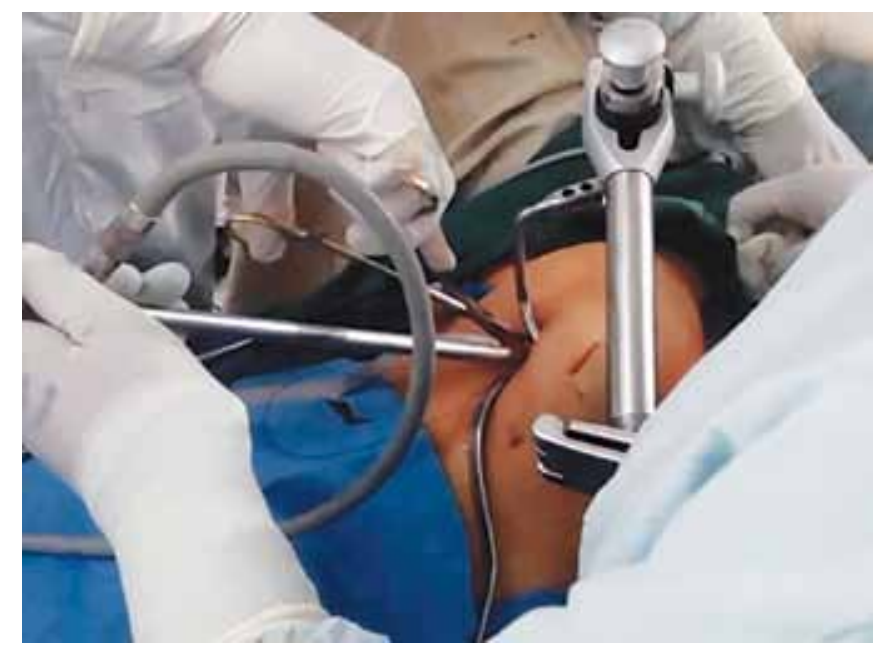

Fig. 6: Lift laparoscopic suturing outside view. The left hand holds the uterine manipulator

pneumoperitoneum in addition to causing physiological changes has small but definite complications. ${ }^{10}$ Several animal studies have documented problems that are associated with use of carbon dioxide for insufflation. ${ }^{11-15}$ Despite the advantages gasless laparoscopic surgery did not become very popular because of the technical difficulty especially due to tenting of the abdominal wall with the available equipment. ${ }^{4}$ The equipment designed by Dr Daniel Kruschinski had the best exposure or vision. ${ }^{16}$ This coupled with steep Trendelenburg position made single incision surgeries possible.

Byron $\mathrm{F}$ et a ${ }^{17}$ reported a study which had compared the performance of standardized tasks from the fundamentals of laparoscopic surgery (FLS) program using either the regular laparoscopic or the single incision laparoscopic surgery (SILS) technique. His study demonstrated that performing tasks using SILS techniques is more technically challenging even for surgeons with previous SILS experience. This is because of crossing of instruments. However with the Lift surgeries familiar

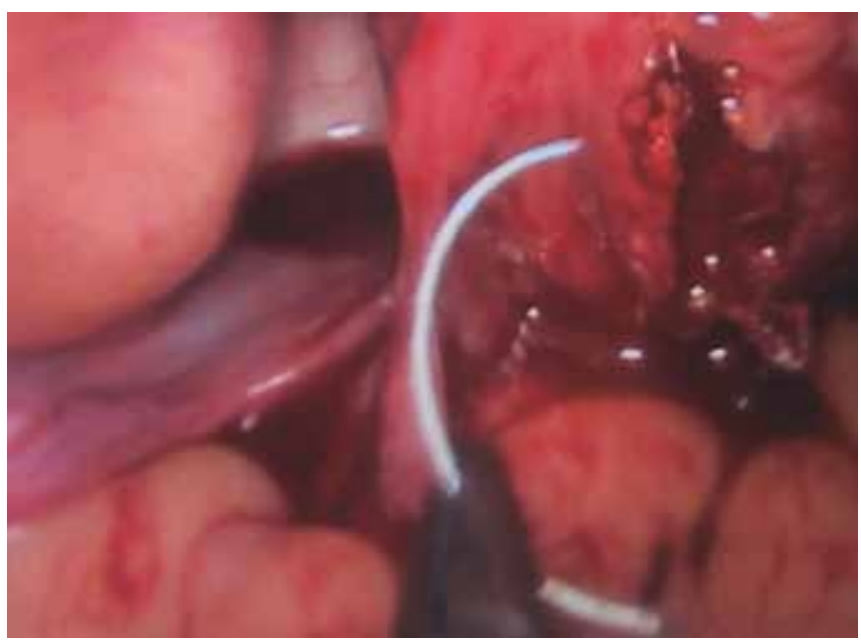

Fig. 5B: Single incision laparoscopic surgery suturing inside view with regular needle holder

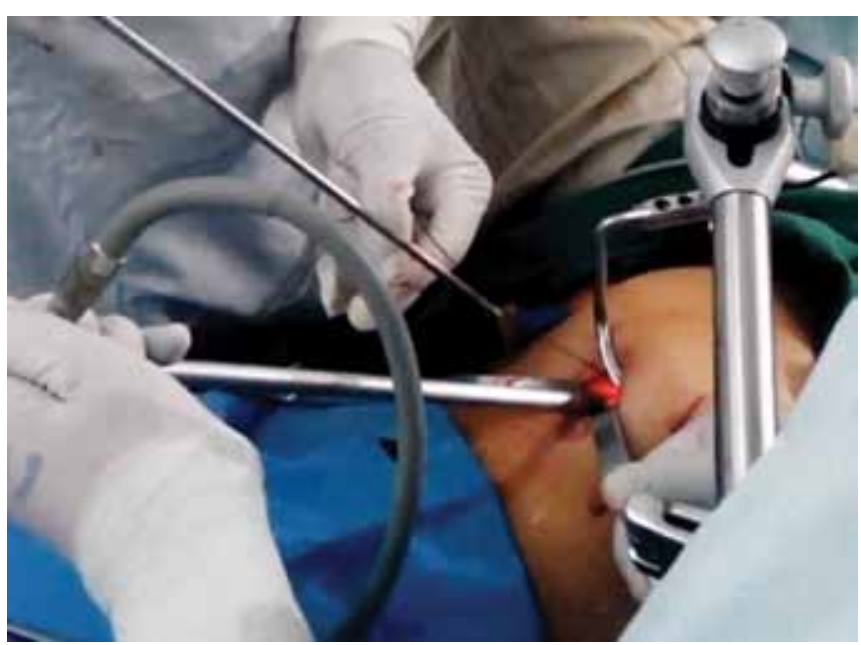

Fig. 7: Extracorporeal tying and pushing with pusher

traditional instruments are used and there is no crossing of instruments.

The lift laparoscopic myomectomy offers a safe and much easier method of surgery that is possible in remote and rural areas. It is much less expensive as it is carried out under spinal anesthesia. The cost of medicines used during spinal anesthesia is around $\$ 10$ to 15 while general anesthesia requires about $\$ 100$. Specially trained anesthesiologist and expensive equipment are necessary for general anesthesia and the disposables used for laparoscopic surgeries are again expensive. It offers all the advantages of single incision laparoscopic surgeries at a very nominal cost.

\section{REFERENCES}

1. Novak ER, Woodruff JD. In gynecologic and obstetric pathology. 8th ed. Philadelphia, USA: WB Saunders. Myoma and other benign tumors of the uterus; 1979. p. 260-278.

2. Desai P, Patel P. Fibroids, infertility and laparoscopic myomectomy. J Gynecol Endosc Surg 2011 Jan-Jun;2(1):36-42. 
3. Semm K, Mettler L. Technical progress in pelvic surgery via operative laparoscopy. Am J Obstet Gynecol 1980;138:121-127.

4. Gnanaraj J, Danita G, Kevin G, Stanley MA, Bravin LR. Gasless or lift laparoscopic surgery equipment: a comparison of available options. MD Current India August 2015. Available at: http://mdcurrent.in/primary-care/gasless-or-lift-laparoscopic-surgery-equipment-a-comparison-of-availableoptions/ [accessed on August 8, 2015]

5. Gnanaraj J, Rhodes M. Instruments for gasless single-incision lift laparoscopic surgery: making laparoscopic surgery available to the poor. MD current India. July 2014. Available at: http://mdcurrent.in/primary-care/instruments-gaslesssingle-incision-lift-laparoscopic-surgery-making-laparoscopic-surgery-available-poor/ [accessed on August 8, 2015]

6. Benecke C, Kruger TF, Siebert TI, Van der Merwe JP, Steyn DW. Effect of fibroids on fertility in patients undergoing assisted reproduction. A structured literature review. Gynecol Obstet Invest 2005;59:225-230.

7. Donnez J, Jadoul P. What are the implications of myomas on fertility? A need for a debate? Hum Reprod 2002;17:1424-1430.

8. Einarsson JI, Jackson TR. Single incision laparoscopic myomectomy. J Minimal Access Surg 2011;7(1):Jan-Mar. p. 83-86

9. BW/F performs World's first single port robotic myomectomy. February 2012. Available at: http://www.brighamandwomens. org/about_bwh/publicaffairs/news/publications/Display Bulletin.aspx?articleid=5474 [last accessed on May 4, 2015]

10. Paulucci V, Gut CN, Schaeff B, Encke A. Gasless laparoscopy in abdominal surgery. Surg Endosc 1995 May;9(5):497-500.
11. De Souza, Wang CC, Chu CY, Lam PM, Rogers MS. The effect of intra-abdominal pressure on the generation of 8-iso prostaglandin F2 alpha during laparoscopy in rabbits. Hum Reprod 2003 Oct;18(10):2181-2188.

12. Izumi K, Ishikawa K, Shiroshita H, Matsui Y, Shiraishi N, Kitano S. Morphological changes in hepatic vascular endothelium after carbon dioxide pneumoperitoneum in a murine model. Surg Endosc 2005 Apr;19(4):554-558. Epub 2005 Feb 10.

13. Latimer FG, Eades SC, Pettifer G, Tetens J, Hosgood G, Moore RM. Cardiopulmonary, blood and peritoneal fluid alterations associated with abdominal insufflation of carbon dioxide in standing horses. Equine Vet J 2003 May;35(3): 283-290.

14. Neuhaus SJ, Watson DI. Pneumoperitoneum and peritoneal surface changes: a review. Surg Endosc 2004 Sep;18(9):13161322. Epub 2004 May 12. Review.

15. Available at: http://www.endometriosis-surgery.org/en/ portal-endogyn/endogyn/surgical-results/adhesions/outcomes/studies-related-to-co2.html (accessed on August 8, 2015).

16. Kruschinski D. Atlas of lift-laparoscopy: the new concept of gasless laparoscopy. Taylor and Francis, 2007 ISBN $0203308379,9780203308370$.

17. Santos BF, Enter D, Nathaniel J. Soper Eric S. Hungness. Single-incision laparoscopic surgery (SILSTM) versus standard laparoscopic surgery: a comparison of performance using a surgical simulator: SurgEndosc 2007;10:1197-1195. 